\title{
A Study to Evaluate the Effectiveness of Planned Teaching Programme on Knowledge Regarding Tetanus and Its Prevention among Farmers
}

\author{
Nidhin Elias \\ Associate Professor, Department of Community Health Nursing, Amrita College of Nursing, Kochi.
}

\begin{abstract}
In India, around $60 \%$ of the population is working in the agricultural field. Farmers in the field may have exposure to different issues like sunburn, injury, snake bite, etc. Injuries lead to tetanus which transmits from soil to the wounded part of the body. As farmers are more subjected to direct contact with soil, transmission rates are often high. The main objective of this study is, assess the knowledge of farmers about tetanus, its prevention and to evaluate the effectiveness of the planned teaching program. A conceptual framework based on Pender's health promotion model involves the analysis by a structured questionnaire to assess knowledge and effectiveness of planned teaching programme.

Material and methods: A quasi-experimental study with 50 farmers was selected from Sikkeri village, Bagalkot with a simple random sampling technique. One group's pre-test \& post-test designs were used in this study. Data collected by structured questionnaires are mainly assessed by knowledge, prevention and effectiveness of planned teaching programme.

Results: The findings indicate that out of 50 members, 29 (48\%) members have satisfactory knowledge and $1(2 \%)$ member have adequate knowledge. However, after the planned teaching programme 45 (90\%) members have adequate knowledge and 5 (10\%) members have satisfactory knowledge.

Conclusion: Early detection and preventive measures among occupational diseases are important. Effective education like a planned teaching programme on tetanus and its prevention among farmers is a scientific, logical, and cost-effective strategy.
\end{abstract}

Keywords: effectiveness planned teaching programme, knowledge, tetanus, prevention, and farmers.

\section{INTRODUCTION}

Farmers are actively involved in economic, livelihood activities of growing crops and primary agricultural commodities like cultivators, tenants, fishers, etc. ${ }^{[1]}$ In India 37 to 118 million people are engaged in different agricultural sectors.

According to FAO, India is the largest producer of many fruits and the secondlargest producer of rice and wheat, the world's major food staples. ${ }^{[3]}$ Over $50 \%$ of the Indian workforce was driven by agriculture and contributed more than $18 \%$ of the country's GDP. But they faced several health issues, especially biological, respiratory, musculoskeletal problems, etc. [4] Tetanus is one of the major health problems in developing and undeveloped countries. It is associated with mortality and morbidity rate with environmental issues, incomplete vaccination action, low educational status, and high case prevalence. According to WHO (2020), worldwide 12459 cases were reported in that 7001 cases were reported in India. ${ }^{[5]}$

A retrospective study hospital-based study was conducted during 2017-2019, Epidemic disease hospital, Banglore. The study result revealed that, out of 58 cases, $87 \%$ of cases were from the rural area. The majority of them are from the agricultural sector $(70 \%)$ (barefoot). The site of injury was the foot $(65 \%)$. So this study concluded 
that proper knowledge and vaccination need to start at all primary health care levels. ${ }^{[6]}$

A cross-section study was conducted in western villages of Turkey within a selection of 293 participants. In that, serum protective tetanus antitoxin level $(>0.1 \mathrm{IU} / \mathrm{ml})$ was detected in 99 out of 293. This study concluded that Farmers of advancing age are at high risk because of their working environment and lesser knowledge about vaccination. ${ }^{[7]}$

A ten-year retrospective study on tetanus at the Epidemic hospital, Mysore shows that out of 512 cases, 75 (14.6) portal of entry was wound and $32(6.2 \%)$ have fissure feet. Mainly it affects farmers due to being barefoot. ${ }^{[8]}$

A retrospective study was conducted in Faridapur Medical College, Bangladesh. Total 80 cases were reported, in that risk factors analyzed by identifiable acute injury in $85 \%$. Prevention during wounds is important to prevent the spread of this disease. ${ }^{[9]}$

The current study has evaluated the effectiveness of the planned teaching programme on knowledge regarding tetanus and its prevention among farmers of Sikkeri Village, Bagalkot District.

\section{Objective:} follows:

The objectives of the study were as

1. To assess the knowledge of farmers regarding tetanus and its prevention.

2. To evaluate the effectiveness of the planned teaching programme regarding tetanus and its prevention.

3. To find out the association between the knowledge regarding tetanus and its prevention with selected demographic variables.

\section{Hypothesis:}

H1: The mean post-test knowledge score of subjects exposed to planned teaching programme on tetanus and its prevention will be significantly higher than their mean pretest score.
$\mathrm{H} 2$ : There will be a significant association between the knowledge regarding tetanus and its prevention among farmers with selected demographic variables.

\section{MATERIALS AND METHODS}

An evaluator approach with the pretest post-test quantitative method was used in the study. The intervention was introduced as one group pre-test and posttest methods. It can show as follows.

$\mathrm{P} 1$....X...P2

P1=Pre test score before introducing intervention.

P2 = Post-test knowledge score after the intervention program.

In this planned teaching programme, tetanus and its preventive measures are independent variables and knowledge of farmers is the dependent variable. Around 50 samples were selected in this simple random sampling method. Farmers who present at the time of study and willingness were used as scale factors in the inclusion criteria. The structured questionnaire consisted of three sections: demographic variable, knowledge and the last session covered preventive measures. The investigator gets permission and ethical clearance from the institution and authorities.

The data obtained were analyzed based on the objective and significant association-based hypothesis acceptance and rejection were analyzed with the inferential statistics based. The plans of data analysis were as follows:

1. Frequency and percentage distribution of farmers according to the demographic variables.

2. Distribution of study subjects according to the level of knowledge in pre-test and post-test.

3. Area-wise analysis of Mean and Standard deviation values per pre and post-test scores of knowledge and its dimension.

4. Comparison of pre and post-test score of knowledge and its dimensions by paired t-test 
Nidhin Elias. A study to evaluate the effectiveness of planned teaching programme on knowledge regarding tetanus and its prevention among farmers.

5. Association between knowledge and demographic variables.

\section{RESULTS}

Table1: Frequency and percentage distribution of farmers according to demographic variables. $n=50$

\begin{tabular}{|l|lll}
\hline Demographic variables & Frequency & (Percentage of
\end{tabular} respondents)

Age(in years)

\begin{tabular}{|l|l|}
\hline Age(in years) \\
\hline $20-29$ years & $20(40 \%)$ \\
\hline $30-39$ years & $24(48 \%)$ \\
\hline 40 years and above & $06(12 \%)$ \\
\hline Gender
\end{tabular}

Gender

\begin{tabular}{|l|l}
\hline Male & $40(80 \%)$ \\
\hline Female & $10(20 \%)$ \\
\hline
\end{tabular}

Work experience (in years)

\begin{tabular}{|l|l|}
\hline Less than 01year & $15(30 \%)$ \\
\hline $01-05$ years
\end{tabular}

\begin{tabular}{|l|l}
\hline $01-05$ years & $22(44 \%)$ \\
\hline 5 years and above & $13(26 \%)$ \\
\hline
\end{tabular}

Education Qualifications

\begin{tabular}{|l|l}
\hline No formal education & $13(26 \%)$
\end{tabular}

\begin{tabular}{|l|l}
\hline Part time/adult education & $09(18 \%)$
\end{tabular}

\begin{tabular}{|l|l}
\hline Primary & $12(24 \%)$ \\
\hline Seconary
\end{tabular}

\begin{tabular}{|l|l}
\hline Secondary & $12(24 \%)$ \\
\hline
\end{tabular}

\begin{tabular}{|l|l|}
\hline Higher Secondary/PUC & $05(10 \%)$ \\
\hline Graduate/Dipoma/Above & $04(08 \%)$ \\
\hline
\end{tabular}

Relgion

\begin{tabular}{|l|l|}
\hline Hindu & $41(82 \%)$ \\
\hline
\end{tabular}

\begin{tabular}{|l|l}
\hline Muslim & $05(10 \%)$ \\
\hline
\end{tabular}

\begin{tabular}{|l|l}
\hline Christian & $05(10 \%)$ \\
\hline
\end{tabular}

\begin{tabular}{|l|l|}
\hline Marital status & \\
\hline Married & $36(72 \%)$ \\
\hline
\end{tabular}

\begin{tabular}{|l|l}
\hline Unmarried & $14(28 \%)$ \\
\hline
\end{tabular}

Duration of work (Hours per day)

\begin{tabular}{l|l}
$0-8$ hours & $04(08 \%)$
\end{tabular}

\begin{tabular}{|l|l}
\hline Above 08 Hours & $46(92 \%)$ \\
\hline
\end{tabular}

\begin{tabular}{|l|l|}
\hline Diet & \\
\hline Mixed & $15(30 \%)$ \\
\hline Vegetarian & $35(70 \%)$
\end{tabular}

Monthly income

\begin{tabular}{|l|l}
\hline$\leq 3000 /-$ & $15(30 \%)$
\end{tabular}

\begin{tabular}{|l|l}
\hline Rs. 3001/- to $10000 /-$ & $21(42 \%)$ \\
\hline Rs. & $10001 /-$ to $17000 /-$ \\
\hline
\end{tabular}

\begin{tabular}{l|l}
\hline Rs. $10001 /$ - to $17000 /-$ & $10(20 \%)$ \\
\hline
\end{tabular}

\begin{tabular}{l|l}
\hline Rs. 17001/- & 04(08\%)
\end{tabular}

Previous history of Tetanus

\begin{tabular}{|l|l|}
\hline Yes & $29(58 \%)$ \\
\hline No & $21(42 \%)$ \\
\hline
\end{tabular}
Demographic variables observed in table: 1 revealed that out of 50 samples, 24 $(48 \%)$ samples belong to 30 to 39 year old and $40(80 \%)$ samples were from males. 22 (44\%) samples were from people with more than 1 to 5 years of experience in the agricultural field but the majority $(13: 26 \%)$ of them have no formal education, most of them are from Hindu religion (41:82\%), marital status - $36(72 \%)$ members were married, 46 members (92\%) work more than 8 hours per day in field, $35(70 \%)$ members are vegetarian in diet and monthly income (21:42\%) lies between Rs.3000 to 10000/-. The next analysis is done, to evaluate the effectiveness of the planned teaching program in the pretest as $29(48 \%)$ of them have only satisfactory knowledge and $20(40 \%)$ have inadequate knowledge. But after the Planned teaching programme's seventh-day post-test score indicates that $45(90 \%)$ of them have adequate knowledge and $05(10 \%)$ of them have satisfactory knowledge. Table 2 clearly describe the comparison score between pre and post-test based on paired t-test. From the result of table 2, pre-test and post-test knowledge scores are found statistically significant $(\mathrm{t}=-$ 41.94, $\mathrm{p}=0.00$ ). It means that the post-test knowledge score $(28.44 \pm 3.06)$ is higher

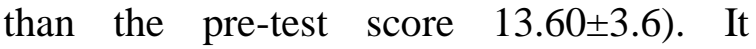
represents post-test scores of total knowledge and its dimensions are higher than pre-test scores.

Table 2: comparison of pre test and post test scores of knowledge and its dimensions by students paired $t$ test

\begin{tabular}{|l|l|l|l|l|l|l|l|}
\hline Variables & Test & Mean & Std.Dev & Mean Diff. & SD.Diff & Paired t value & p-value \\
\hline Knowledge & Pre test & 7.2200 & 2.75011 & -8.640 & 2.1390 & -26.3445 & $0.0 *$ \\
\hline About Tetanus & Post test & 15.860 & 2.0405 & & & & \\
\hline Knowledge & Pre test & 6.3800 & 1.9989 & -6.20 & 2.2315 & -19.6463 & $0.0^{*}$ \\
\hline About Prevention of tetanus & Post test & 12.580 & 1.7034 & & & & \\
\hline Total & Pre test & 13.600 & 3.6365 & & & & -41.9417 \\
\hline Knowledge & Post test & 28.440 & 3.0583 & -14.840 & 2.5019 & & 0.0 \\
\hline
\end{tabular}

The multiple regression analysis showed that pre-test and the post-test score of age, gender, exposure of tetanus, and monthly income significantly associated between knowledge and its preventive measures, but the duration of work pre-test and post-test score along with work experience, diet, educational qualification, and marital status pre-test knowledge have no significant association.

\section{DISCUSSION}

This study shows that, out of 50 farmers, 29 have previous experience of 
tetanus. A similar study was conducted about tetanus seroprevalence among farmers shows that out of 102 subjects antiTT concentration for the farmers (median=2.74IU/ml) were higher compare to the general population. ${ }^{[10]}$

This study shows that farmers have (mean:7.22) little knowledge about tetanus and its preventive measures. A similar study conducted by Ricco M, Razio B, Panato C, etc conducted a study about knowledge, attitude, and practices of agricultural workers toward tetanus vaccine. Total 707 participants attended this study, only $370(52.3 \%)$ gave proper answer about their knowledge in tetanus which shows that half of them have inadequate knowledge its preventive measures. ${ }^{[11]}$

This study shows that knowledge about tetanus post-test score is higher $(15.86 \pm 2.04)$ as compared to $(7.22 \pm 2.75)$ pre-test scores. Also in terms of knowledge about prevention of tetanus, the post-test scores are higher $(12.58 \pm 1.70)$ as compared to $(6.8 \pm 2)$ pre-test score. So it shows that knowledge about tetanus and preventive measures increased after the planned teaching programme. A similar study shows that, a quasi-experimental study about the effectiveness of structured teaching programme to assess the mothers' knowledge regarding vaccine-preventable disease among children. This study result shows that, out of 112 mothers, knowledge about vaccination (12.88 3.51) was poor, after teaching programme (27.12 3.89) which $66.14 \%$ of the total score revealing good knowlege. ${ }^{[12]}$

\section{CONCLUSION}

This study helped farmers to improve their knowledge regarding tetanus and its prevention. The investigator concluded that tetanus is one of the communicable diseases, is to be taken off from our country by conducting preventive programme and enable diagnosis before the development of the disease. So community field workers can prevent any disease with a proper awareness program with optimum utilization of the health care system.

\section{Support and sponsorship: Nil.}

\section{Acknowledgement: None}

Conflict of Interest: There are no conflicts of interest.

\section{Ethical Approval: Approved}

\section{REFERENCES}

1. National Policy for Farmers Department of Agriculture \& Cooperation. Ministry of Agriculture. Government of India. Accessed on 22 March 2021.PP4.

2. Agarwal, Kabir (9 March 2021). "Indian Agriculture's Enduring Question: Just How Many Farmers Does the Country Have?"; The Wire;Retrieved 22 March 2021. Available from https://thewire.in/agriculture/indianagricultures-enduring-question-just-howmany-farmers-does-the-country-have

3. "FAOSTAT, 2014 data". Faostat.fao.org. Retrieved 17 September 2011.

4. Edmond Fernandes. Farmer's health: The conscience call for actionJanuary;TOI:29, 2020. Available from https://timesofindia.indiatimes.com/blogs/gl obal-health-focus/farmers-health-theconscience-call-for-action/

5. WHO. Tetanus (total) reported cases: 15Oct-2020. Available from https://apps.who.int/immunization_monitori ng/globalsummary/timeseries/tsincidencettet anus.html;

6. Feroz AHM, Hafizur Rahman.Ten-year Retrospective Study of Tetanus at a Teaching Hospital in Bangladesh. Bangladesh Journals Online. Available from https:// www.banglajol. info/ index.php/JBCPS/article/view/371

7. SerkanÖncü, Mete Önde,Selcen Önci, FilizErgin et al. Tetanus seroepidemiology and factors influencing immunity status among farmers of advanced age. Health policy. volume 100;issue 2-3; May 2011;Page No 305-30. Available from https://www.sciencedirect.com /science/article /abs/pii/S0168851010003581\#! 
Nidhin Elias. A study to evaluate the effectiveness of planned teaching programme on knowledge regarding tetanus and its prevention among farmers.

8. Vamadeva Giriyapura Marulappa,Renuka Manjunath,Nakul Mahesh Babu,and Laxman Maligegowda.Ten Year Retrospective Study on Adult Tetanus at the Epidemic Disease (ED) Hospital, Mysore in Southern India: A Review of 512 Cases. Journal of clinical and diagnostic research. Published online 2012 Oct 10. Available from https://www.ncbi.nlm.nih. gov/pmc /articles /PMC3471487.

9. Srikanth V.S ,Naidu Shravanthi, Ansar Ahmed,Tippeswammy and Mul V.R.Indian experience of tetanus - A study from south India. Romanian Journal of Military Medicine.Vol;CXXIV ;No. 1/2021; February.

10. Mary S Hayney 1, Gayle Dienberg Love, Beth M Carlberg, Jessica M Buck and Daniel Muller. Tetanus seroprevalence among farmers: a preliminary study. Journal of rural health. Available from https://pubmed.ncbi.nlm.nih.gov/12696846/
11. Riccò M,Razio B,Panato C,Poletti L and Signorelli C.Attitudes and Practices of Agricultural Workers towards Tetanus Vaccine: a Field Report.Ann Ig.Jul-Aug 2017;29(4): 239-255 ;doi: 10.7416/ai. 2017.2156 .Available from https://pubmed.ncbi.nlm.nih.gov/28569334.

12. Binu joe, Mrs. Anu Joykutty. Effectiveness of Structured Teaching Programme to Assess Knowledge of Mothers Regarding Vaccine Preventable Disease Among Children. International Journal of Immunological Nursing,vol5,No1(2019).

How to cite this article: Elias N. A study to evaluate the effectiveness of planned teaching programme on knowledge regarding tetanus and its prevention among farmers. International Journal of Research and Review. 2021; 8(10): 252-256. DOI: https://doi.org/10.52403/ijrr. 20211033 